
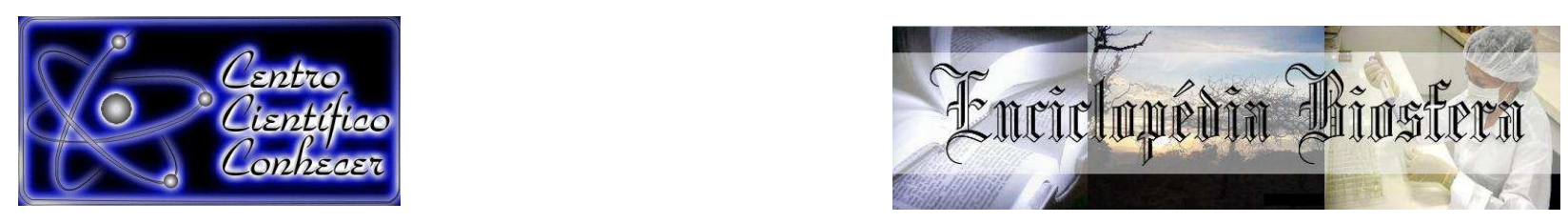

\title{
EFEITO DA EXPOSIÇÃO À RADIAÇÃO IONIZANTE SOBRE O DNA: UMA AVALIAÇÃO CIENCIOMÉTRICA
}

Grazziela Alves Ferreira de Oliveira'; Emília Oliveira Alves ; Flávia Melo Rodrigues $^{1 ; 2}$

${ }^{1}$ Mestrado em Genética da Pontifícia Universidade Católica de Goiás. Goiânia - Goiás - Brasil. (grazzibio@hotmail.com)

2 Departamento de Biologia da Universidade Estadual de Goiás e da Pontifícia Universidade Católica de Goiás.

Recebido em: 08/04/2017 - Aprovado em: 10/06/2017 - Publicado em: 20/06/2017 DOI: 10.18677/EnciBio_2017A109

\begin{abstract}
RESUMO
A radiação ionizante quando interage com a matéria remove um elétron de seu orbital, formando íons ou partículas ionizadas. Quando um indivíduo é exposto a radiações ionizantes, existe a possibilidade de se produzir danos para o organismo, danos reversíveis ou não, dependendo basicamente do tempo de exposição, do nível de dano e da dose absorvida. Esse trabalho teve como objetivo caracterizar a produção científica sobre danos genéticos causados por radiações ionizantes, desde o ano de 1970 até o ano de 2014 a fim de verificar as tendências e perspectivas do desenvolvimento científico por meio da análise cienciométrica. Para isso foi realizado um levantamento bibliográfico no sítio Scopus®, utilizando as palavraschaves "ionizing radiation" and mutation and effects and human. Foram realizadas diferentes dados os artigos: tipo de publicação, número de artigos/ano, periódicos que mais publicaram e patologias abordados nos estudos. Constatou-se um aumento no número de publicações relacionadas aos danos no DNA e radiação ionizante no decorrer dos anos. A maior parte dos trabalhos foi desenvolvida por autores de origem dos Estados Unidos da América (42\%). A maioria dos artigos relacionou seus achados ao desenvolvimento do câncer (41\%). O estudo mostra que há interesse em relação ao estudo de danos no DNA causados por radiação ionizante, uma vez que estes danos podem ser responsáveis por inúmeros efeitos biológicos desfavoráveis à saúde humana.
\end{abstract}

PALAVRAS-CHAVE: Cienciometria; Danos ao DNA; Mutação.

\section{EFFECT OF EXPOSURE TO IONIZING RADIATION ON DNA: A SCIENTIFIC ASSESSMENT}

\begin{abstract}
lonizing radiation, when interacting with matter, removes an electron from its orbital and generates ions or ionized particles. When an individual is exposed to ionizing radiation, reversible or irreversible harms to the body may arise, depending basically
\end{abstract}


on the exposure time, level of injury, and absorbed dose. This study aimed to characterize the scientific literature on genetic damage caused by ionizing radiation, from 1970 to 2014, in order to verify trends and prospects of scientific development through scientometric analysis. This was accomplished through a literature search on the site Scopus® using the keywords "ionizing radiation" AND mutation AND effects $A N D$ human. Different approaches of paper assessment were carried out: type of publication, number of articles/year, number of publications per journal, and conditions discussed in the studies. As a result, there was an increase in the number of publications related to DNA (Deoxyribonuclei acid) damage and ionizing radiation over the years. Most of the work was developed by authors from the US (42\%). Most papers correlated their findings to cancer development $(41 \%)$. It was also observed that there was an increase in the number of publications over the years, leading to the conclusion that there is interest in the study of DNA damage caused by ionizing radiation, since this damage may be responsible for numerous adverse biological effects on human health.

KEYWORDS: Scientometrics; Damage to the DNA; Mutation.

\section{INTRODUÇÃO}

O termo radiação ionizante $(\mathrm{RI})$ corresponde ao transporte de energia realizada na forma de ondas eletromagnéticas ou de partículas subatômicas que tem a capacidade de produzir ionização da matéria, gerando energia, ou seja, são aquelas radiações que, ao atravessar a matéria, interagem com os átomos, ionizando-os (FLOR \& KIRCHHOF 2006). Essa ionização da matéria, segundo WUEHRMANN \& MANSON-HIG (1985), pode afetar os tecidos vivos quando estes passam pelo processo que transformam os átomos e as moléculas eletricamente estáveis em eletricamente instáveis.

Quando um indivíduo é exposto a radiações ionizantes, existe a possibilidade de se produzir danos para o organismo, tanto em células somáticas quanto em germinativas e, devido a esta exposição vários danos genéticos podem ser causados (ARDENGHI et al., 2003). Como consequência da interação da radiação com a matéria ocorre transferência de energia, o que pode provocar ionização e excitação de átomos e moléculas associadas, ocasionando alterações que podem ser temporárias ou permanentes nestas células, levando consequentemente aos efeitos biológicos (VELUDO, 2011).

Os efeitos biológicos são respostas naturais do organismo a um agente agressor, ou seja, é o resultado da interação da radiação com a matéria e pode ser reversível ou não dependendo basicamente do tempo de exposição, do nível de dano e da dose absorvida (estocástico ou determinístico) (VELUDO, 2011). A preocupação a respeito dos possíveis efeitos adversos provenientes das radiações, nos últimos anos tem sido crescente.

Há consenso por parte da comunidade científica de que altas doses de radiação têm potencial capacidade de produzir danos genéticos ao organismo (ARDENGHI et al., 2003). Diante da relevância deste tema é evidente a importância de se quantificar e caracterizar a produção científica sobre o assunto.

A cienciometria é um instrumento, de medida, baseado em técnicas estatísticas, que tem por objetivo identificar e tratar as informações contidas nas publicações científicas e técnicas, disponíveis nos sistemas de informação, 
essencialmente, referências bibliográficas de artigos, de livros e de patentes; razão pela qual torna-se importante analisar o papel destas diferentes publicações nas atividades dos pesquisadores. Alguns índices como frequência de artigos e citação destes em bases de dados indexadas são as ferramentas da cienciometria (NONATO, 2003).

A publicação dos resultados de suas pesquisas é um compromisso que os cientistas devem cumprir e o notável avanço do conhecimento produzido pelos pesquisadores tem de ser transformado em informação cada vez mais acessível para toda a comunidade científica (MACIAS-CHAPULA, 1998). Nesse sentido, o levantamento cienciométrico das publicações sobre danos genéticos causados por radiações ionizantes permite reconhecer os principais grupos de pesquisadores, instituições e países que publicam sobre o tema. Além de identificar as tendências de produção científica na área.

Considerando a enorme quantidade e acessibilidade da produção científica nas diversas áreas do conhecimento, aliado a importância e relevância do tema discutido, torna-se necessário caracterizar as publicações sobre os danos genéticos causados pelas radiações ionizantes, fazendo uma análise cienciométrica. $O$ presente estudo teve o objetivo de quantificar a produção científica sobre danos no DNA causados pela radiação ionizante.

\section{MATERIAL E MÉTODOS}

Para a análise quantitativa dos estudos sobre radiações ionizantes e danos genéticos foi utilizada a produção bibliográfica como indicador dos resultados obtidos nos últimos 43 anos. O levantamento dos estudos foi realizado por meio do banco de dados publicado no sítio do Scopus®, utilizando as palavras-chave "ionizing radiation" and mutation and effects and human". Utilizou-se a forma composta porque separadamente os termos podem indicar uma variedade enorme de trabalhos não relacionados aos assuntos interligados, portanto não se enquadrariam aos objetivos deste estudo. Foram buscados artigos até dezembro de 2014. Foi utilizado o Scopus® devido a sua abrangência quanto ao número de publicações e qualidade dos periódicos indexados.

A partir das publicações selecionadas foram levantadas as seguintes informações:

(i) ano de publicação do artigo;

(ii) tipo de documento publicado;

(iii) autores que mais publicaram;

(iv) artigos mais citados;

(v) periódico em que o artigo foi publicado;

(vi) fator de impacto do periódico que publicou o artigo;

(vii) países onde foram realizados os estudos;

(xiii) idiomas usados para publicação;

(ix) patologias associadas aos danos genéticos.

Informações das patologias associadas foram obtidas através da leitura dos abstracts. Alguns artigos não disponibilizam os abstracts ou não estavam diretamente relacionados ao tema proposto por isso foram excluídos, ou ainda não apresentavam tais informações. 
O fator de impacto $(\mathrm{FI})$ dos artigos utilizados nas análises foi obtido a partir do Journal Citation Reports (JCR) para o ano mais recente citado. O FI é um indicador utilizado para calcular o número médio de citações recebidas por um periódico científico e é obtido por meio da relação entre o número de vezes que o periódico foi citado e o número de artigos publicados num determinado período de tempo, normalmente dois anos. A finalidade da utilização deste indicador é descobrir o impacto dos periódicos na comunidade científica (THOMAZ et al., 2011).

Em seguida, os dados foram organizados e tabulados em uma planilha de Excel de acordo com cada variável da pesquisa, conforme já mencionado. Após a tabulação dos dados, os mesmos foram analisados por meio de estatística descritiva (variáveis categóricas) e correlação de Pearson para avaliar as seguintes associações:

- Número de publicações por ano;

- Tipo de artigo e Fator de Impacto;

- Fator de impacto e ano;

- Fator de impacto e número de autores;

- Número de citações por ano e;

- País e número de citações.

Adotou-se um nível de significância de 0,05 para todas as análises. $O$ teste do Qui-quadrado foi usado para verificar diferenças significativas entre o país e o número de citações; fator de impacto e organismo e tipo de documento. Todas as análises foram realizadas no programa Bioestat 5.0 (AYRES et al., 2007).

\section{RESULTADOS E DISCUSSÃO}

De acordo com o levantamento realizado, foram encontrados 953 trabalhos publicados no período de 1970 a 2014 utilizando as palavras "ionizing radiation" and mutations and effects and human". Após a leitura dos abstracts dos 953 artigos encontrados, 655 foram excluídos, pois estes não estavam diretamente relacionados à radiação ionizante e os danos no DNA, sendo selecionados 298 como número amostral.

O número de publicações cresceu de forma significativa $(\mathrm{p}<0,0001)$ a partir do ano 2000, com um pico no ano de 2013 (35 artigos) (Figura 1). O número de publicações é utilizado como medida para quantificar o progresso e evolução da ciência, assim sendo, o crescimento progressivo do conhecimento científico foi positivamente relacionado com o aumento do número de artigos (VERBEEK et al., 2002).

Segundo HEY et al., (2009), o aumento no número de publicações pode ser atribuído à disponibilidade de trabalhos, pesquisas e projetos na internet. Além dessa facilidade à informação proporcionada pela internet, outro fator que pode estar relacionado ao aumento na puplicação de dados sobre os danos no DNA causados pela radiação ionizate é o interesse pelo fato de que essa radiação pode causar vários danos ao organismo (AYRES et al., 2007). Logo, como demonstrado nestes dados, é possível afirmar que há interesse por parte dos pesquisadores em estudar os danos no DNA causados pela radiação ionizante, devido ao número de publicações na área serem crescentes ao longo dos anos. 


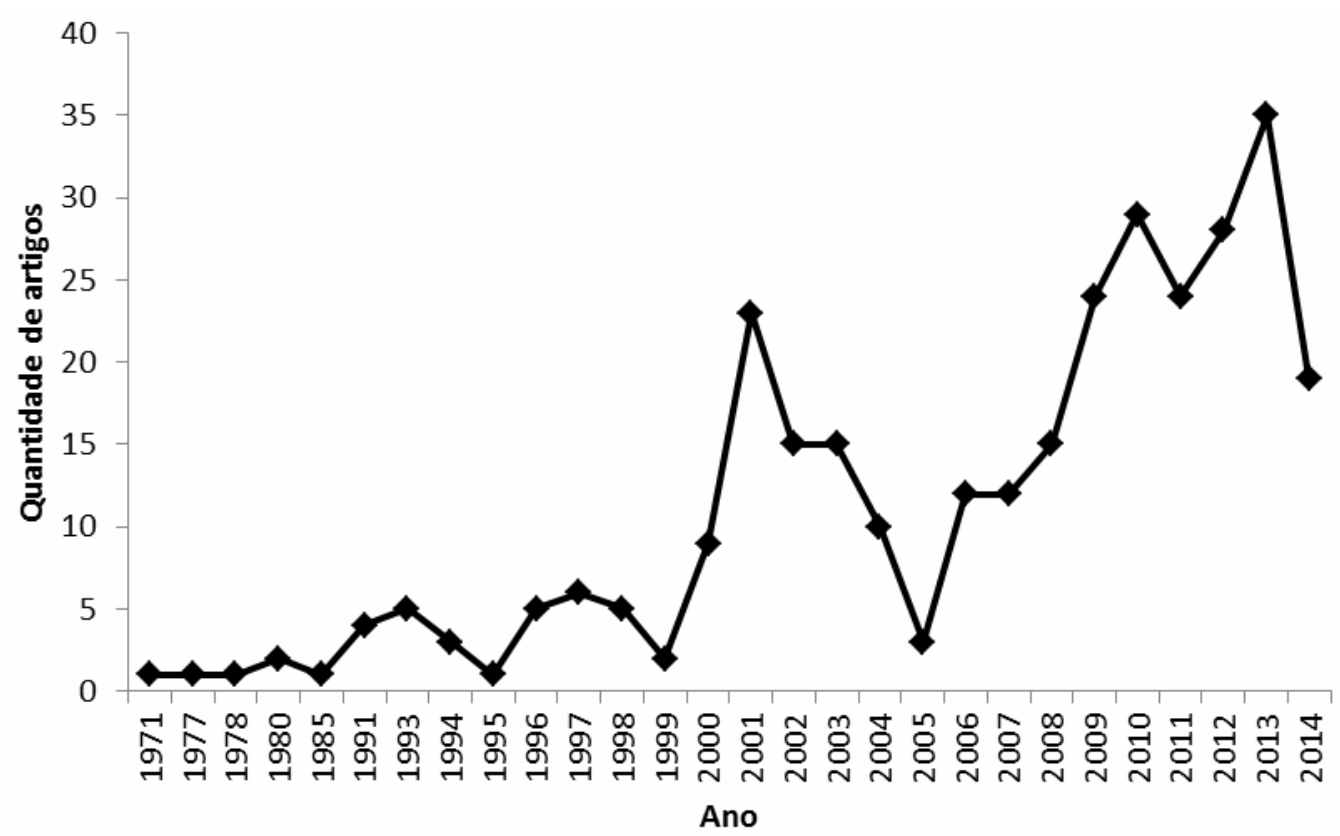

FIGURA 1. Número de artigos publicados, na área da Genética, abordando a radiação ionizante e os danos causados no DNA, indexados no Scopus ${ }^{\circledR}$. $(r=0,8837 p=<0,0001)$

Em um total de 298 publicações, 56 foram artigos de revisão e 242 foram artigos originais, perfazendo um total de $81 \%$ (Figura 2), demonstrando que houve interesse em utilizar a radiação ionizante aliada a danos genéticos. Trabalhos em diferentes áreas demonstram que estudos de revisão são menos frequentes que estudos experimentais ou originais (CARNEIRO et al., 2008; QUIXABEIRA et al., 2010). O tipo de publicação (artigo original ou artigo de revisão) não apresentou associação com o FI das revistas ( $p=0,1159)$ (Tabela 1).

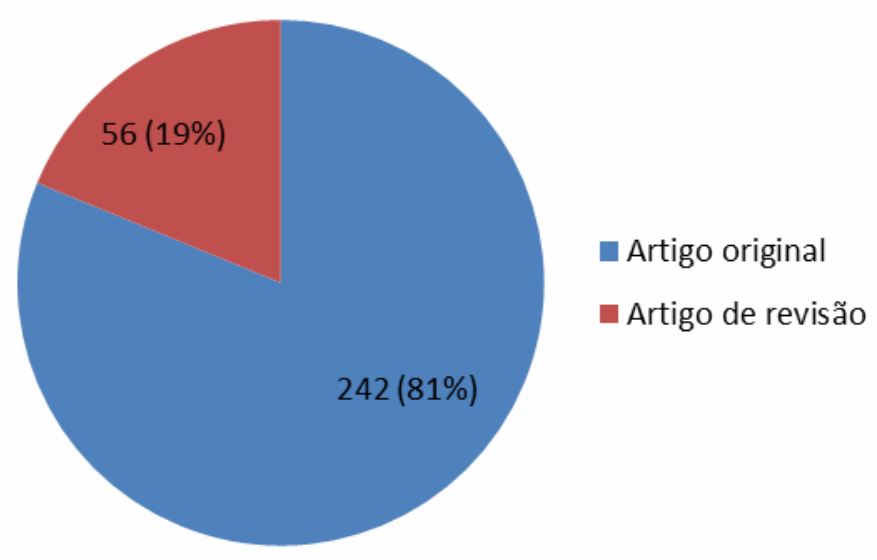

FIGURA 2. Distribuição dos estudos sobre radiação ionizante e os danos no DNA na área da Genética de 1970 a 2014, segundo o tipo de publicação. 
TABELA 1. Relação entre o Fator de Impacto e o tipo de documento das publicações sobre danos genéticos causados por radiações ionizantes.

\begin{tabular}{|c|c|c|c|}
\hline \multirow{2}{*}{ Tipo de documento } & \multicolumn{2}{|c|}{ Fator de Impacto } & \multirow{2}{*}{$p^{*}$} \\
\hline & $\geq \mathbf{3 , 0}$ & $<3,0$ & \\
\hline Artigo Original & $142(84 \%)$ & 57 (75\%) & \multirow{2}{*}{0,1159} \\
\hline Artigo de Revisão & $28(16 \%)$ & $19(25 \%)$ & \\
\hline
\end{tabular}

$\mathrm{Na}$ avaliação do número de periódicos e o total de artigos, observou-se que um total de 158 diferentes periódicos publicaram sobre o assunto estudado. Porém, somente seis periódicos obtiveram um número de publicações igual ou superior a 10 trabalhos, perfazendo um total de 83 artigos (Figura 3). Dentre os periódicos com alta taxa de publicações, observou-se que o periódico Mutation Research publicou 27 artigos, o que corresponde a um total de $32 \%$ das publicações.

Mutation Research é um periódico científico que publica trabalhos de pesquisa na área de mutação que incidem sobre mecanismos fundamentais subjacentes à expressão fenotípica e genotípica de danos genéticos. As publicações deste periódico datam desde 1964 até o presente momento, com uma frequência estimada em 60 trabalhos por ano (WORLDCAT, 2016). O periódico Mutation Research, assim como os seis periódicos ranqueados neste trabalho, apresentam um enfoque multidisciplinar, o que confirma essa característica em estudos com radiação ionizante e os danos genéticos causados ao DNA.

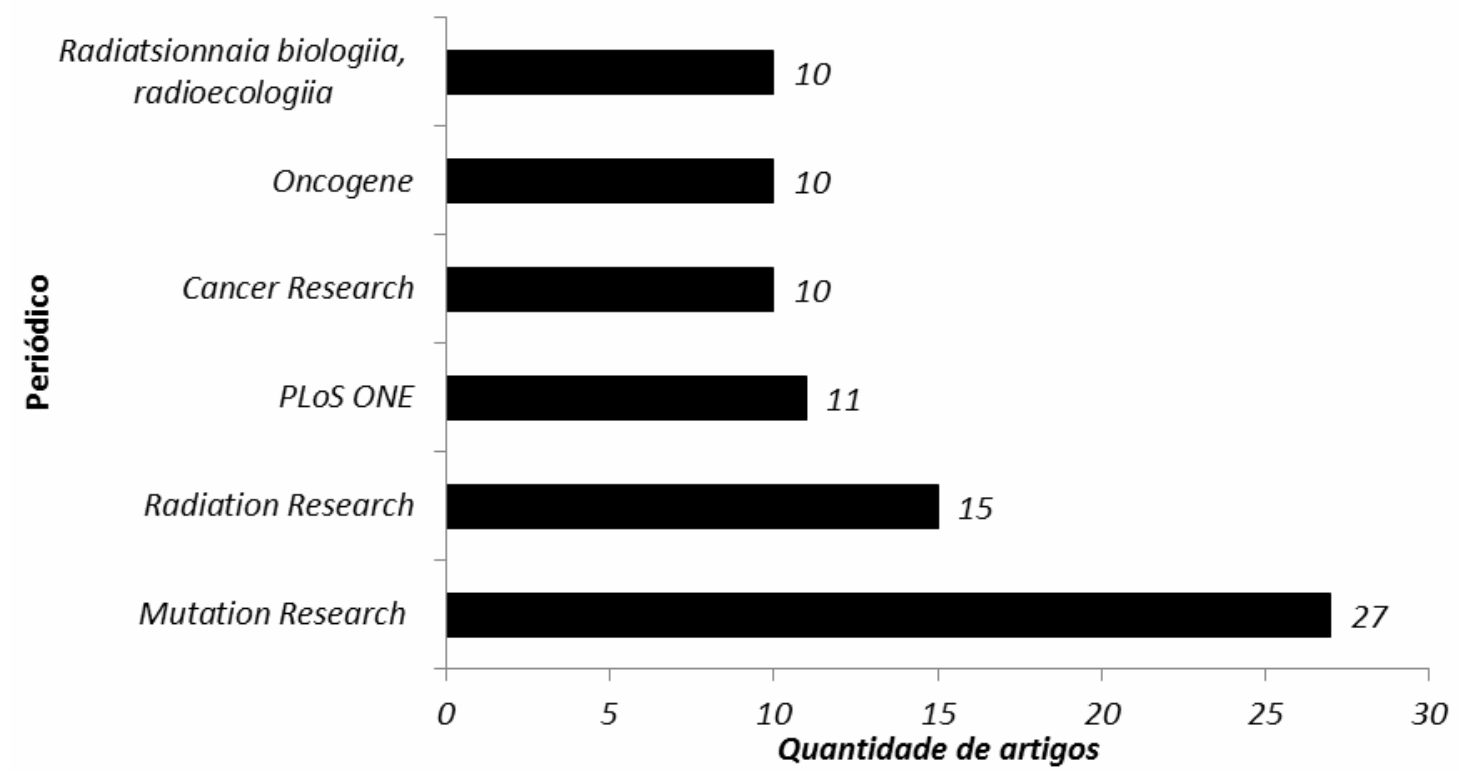

FIGURA 3. Periódicos com frequências de publicação maior ou igual a 10 artigos.

Quanto ao fator de impacto (FI), verificou-se que dentre os 298 periódicos utilizados nas análises, 256 apresentavam um valor médio de 4,64 variando de 0,09 a 44. O periódico com o maior número de publicações, a Mutation Research, apresentou um FI de 5,261. Dentre os periódicos que mais publicaram, com exceção da Radiatsionnaia biologiia, radioecologiia, todos apresentavam FI acima de três 
(Figura 4). Assim sendo, os resultados evidenciam um considerável impacto do assunto pesquisado na comunidade científica. Não houve correlação significativa entre $\circ \mathrm{Fl}$ e 0 ano, ( $r=-0,0081$ e $p=0,8974)$ (Figura 4). Segundo THOMAZ et al., (2011), o Fl firmou-se como meio de avaliação dos periódicos.

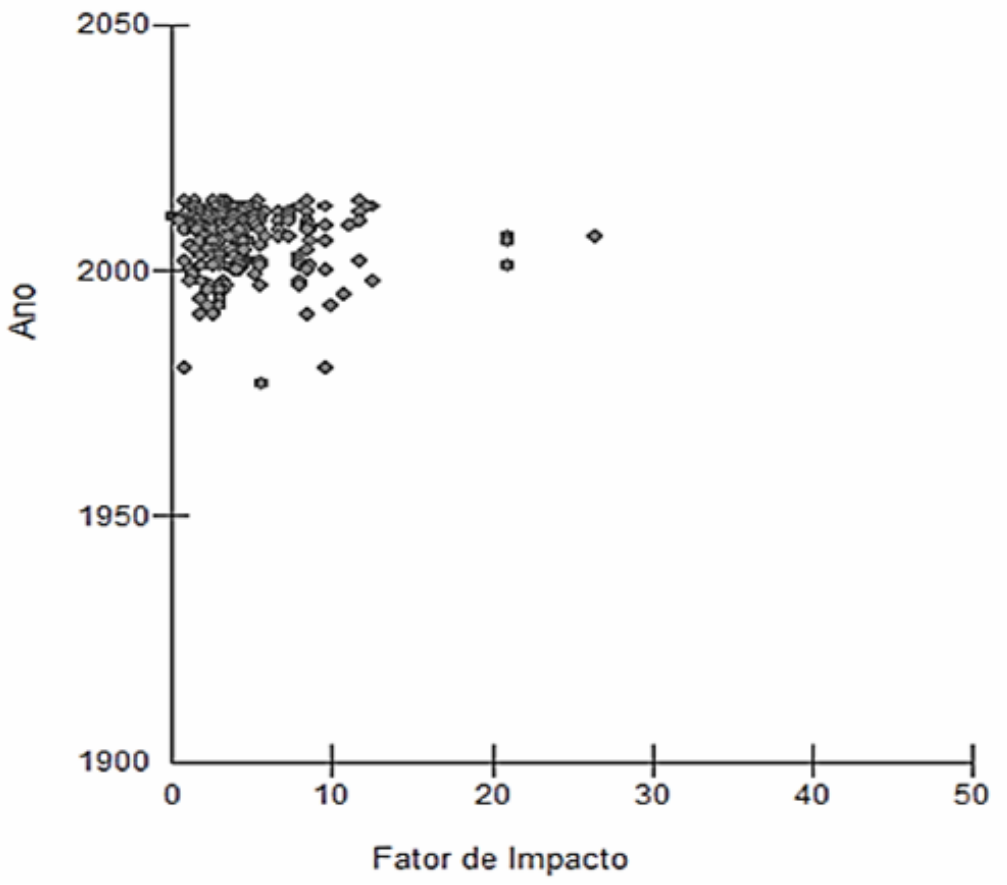

FIGURA 4. Correlação de Spearrman entre o fator de impacto e ano dos periódicos com frequência de publicação maior ou igual a 10 artigos.

O número de autores variou de um a 36 , perfazendo uma média de $5,5( \pm 4,2)$ autores por publicação. Quando analisada a relação entre o Fator de Impacto e o número de autores não houve correlação significativa $(r=-0,0426, p=0,4982)$ (Figura 5).

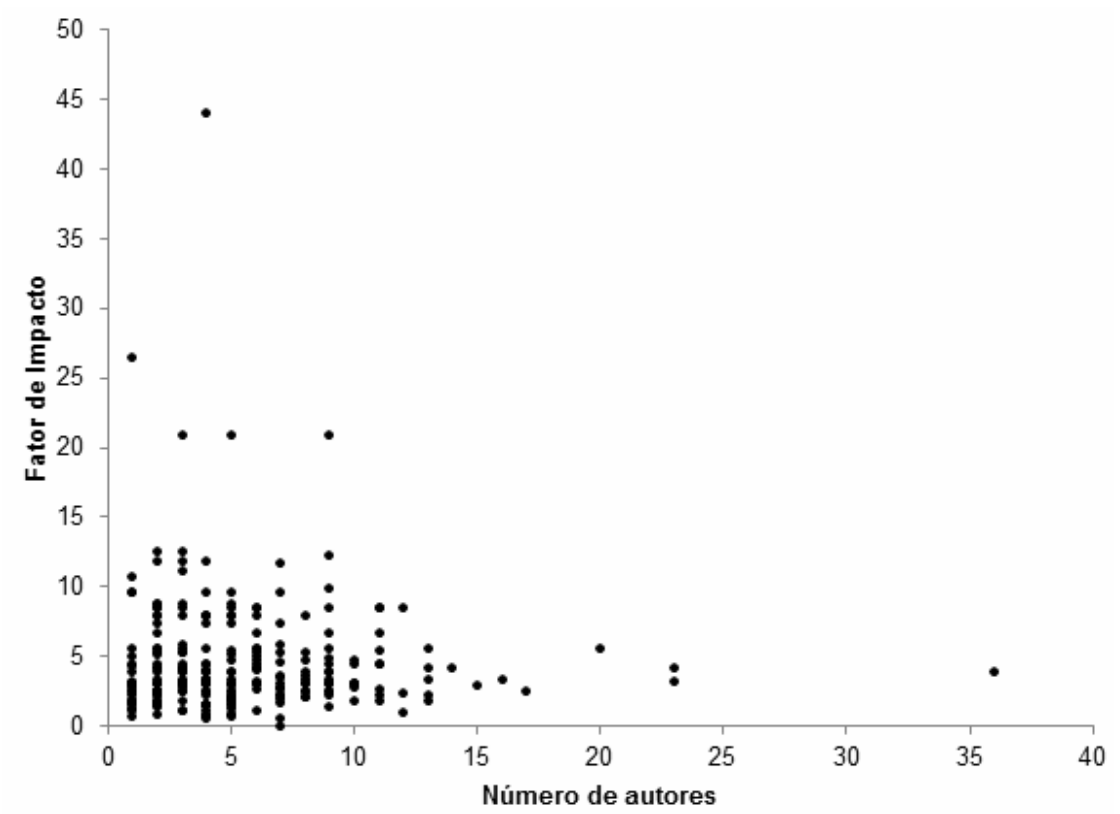

FIGURA 5. Correlação do número de autores das publicações analisadas com o Fator de Impacto. 
Entre os 298 artigos, 271 foram citados ao menos uma vez, as citações variaram de uma a 1.835 , perfazendo uma média de 38.24 ( \pm 119.75$)$ citações. Houve correlação negativa significativa $(r=-0,1324 p=0,0303)$ (Figura 6) entre 0 número de citações e ano, ou seja, com o passar do tempo o número de citações tende a diminuir.

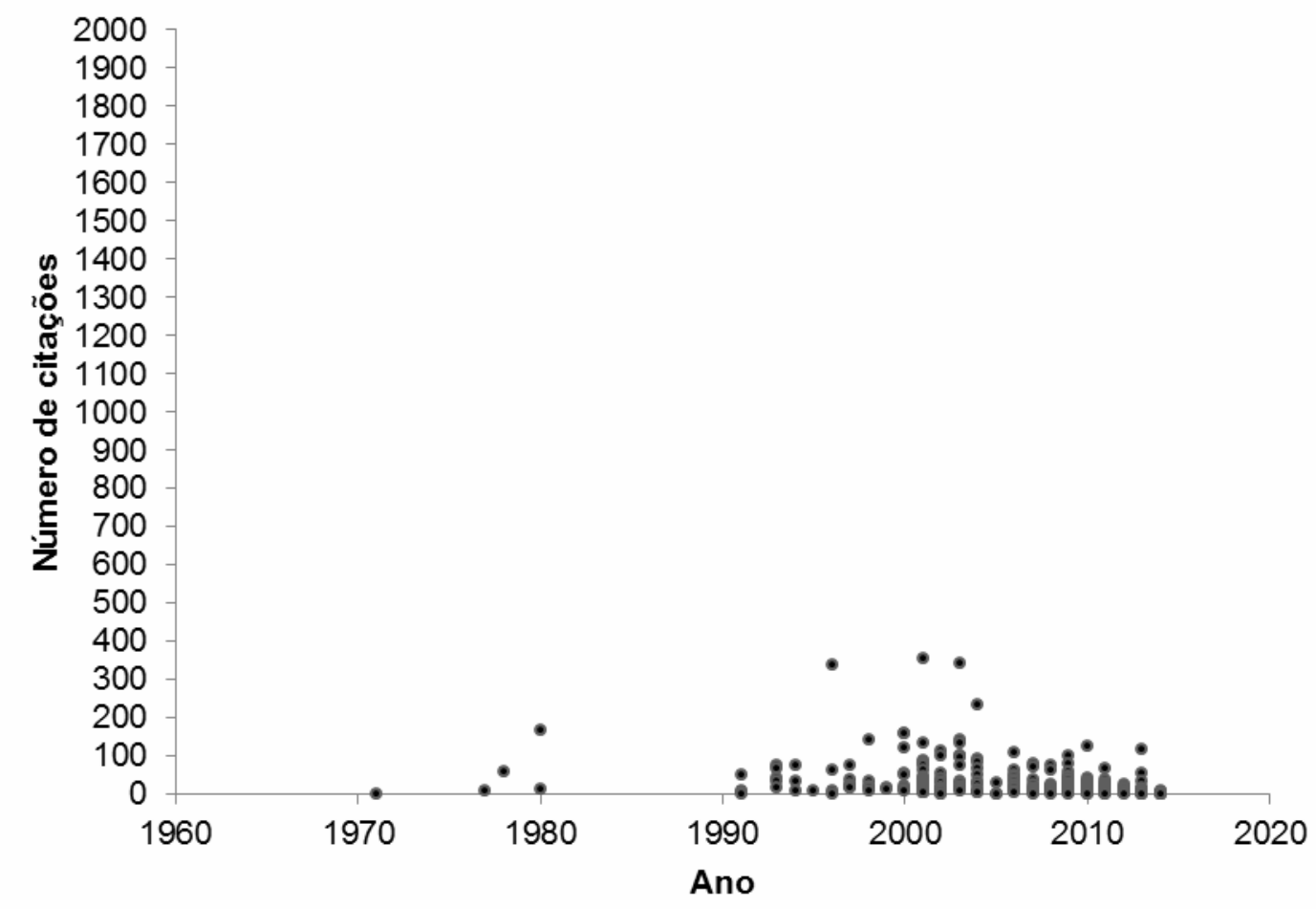

FIGURA 6. Correlação entre o número de citações dos periódicos analisados. $(r=0,1324 p=0,0303)$

Observou-se que os cinco países que mais publicaram artigos sobre radiação ionizante e danos no DNA no campo da genética no período de 1970 a 2014 (Figura 7) equivalem a aproximadamente $72 \%$ do total de publicações. Verificou-se que os EUA aparecem com 124 artigos, o que equivale a $42 \%$ das publicações seguido, em ordem decrescente por Japão, Reino Unido, Alemanha e França com 32, 25, 21, e 13 artigos respectivamente, o Brasil, apresentou apenas quatro publicações (1\%).

O número de citações dos artigos não está associado aos países que mais publicam $(p=0,6604)$ (Tabela 2). De acordo com CARNEIRO et al.,(2008), o grande número de publicações por países desenvolvidos é o reflexo da infraestrutura e investimento desses países em pesquisa. Os resultados são semelhantes àqueles encontrados por QUIXABEIRA, et al., (2010), quando demonstraram que o número de publicações com a citometria foi maior em países desenvolvidos.

Os demais países (Japão, Reino unido, Alemanha e França), que são países desenvolvidos, seguem o mesmo princípio, demonstrando que o investimento em ciência está diretamente relacionado com a formação e qualificação de pesquisadores, mestres e doutores titulados (LIMA-RIBEIRO et al., 2007). Diante disso, ficou claro que países em desenvolvimento, como o Brasil, continuam enfrentando dificuldades para realizar pesquisas. Outro aspecto importante é a migração dos cientistas para países desenvolvidos, devido a melhores vantagens 
financeiras aliadas a melhor infraestrutura em relação ao seu país de origem (CURRÁS \& BARREIRO, 2008).

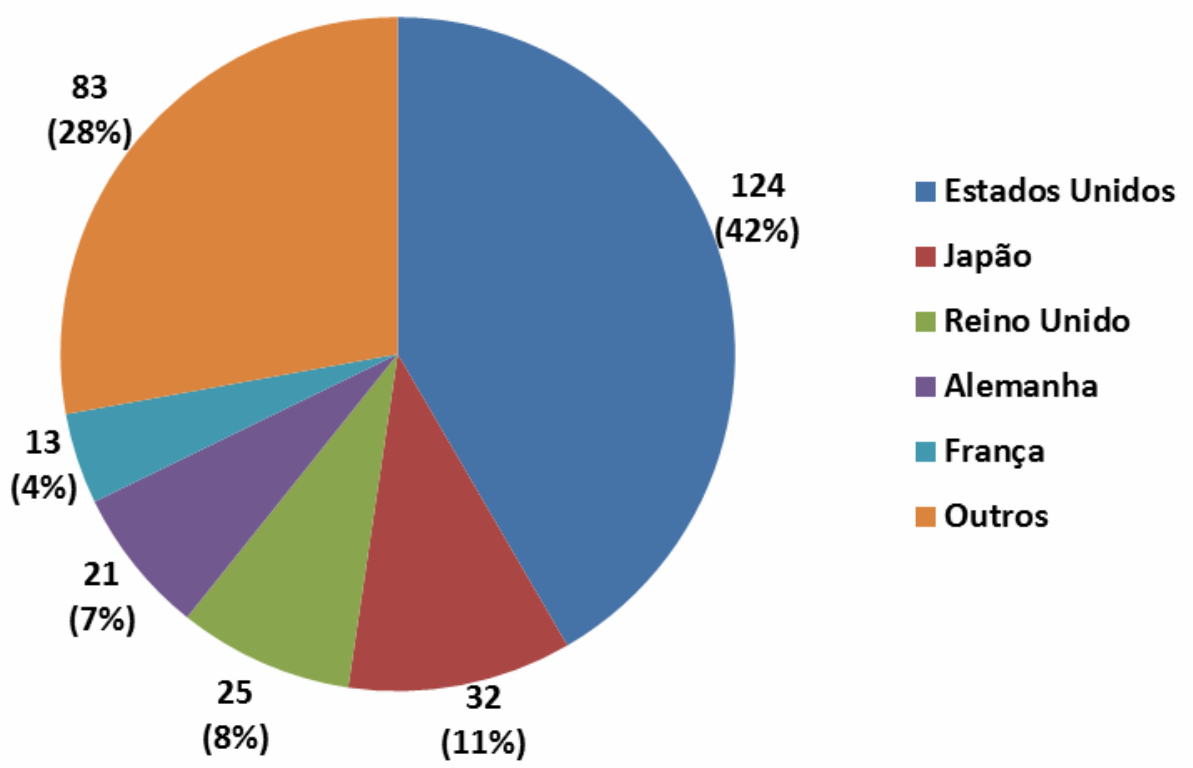

FIGURA 7. Países que mais publicaram artigos sobre radiação ionizante e danos no DNA no campo da genética no período de 1970 a 2014.

Não houve diferença significativa quanto ao número de citações e país das publicações sobre danos genéticos causados por radiações ionizantes $(p=0,6604)$ (Tabela 2).

TABELA 2. Relação entre o número de citações e o país das publicações sobre danos genéticos causados por radiações ionizantes.

\begin{tabular}{lccc}
\hline \multirow{2}{*}{ País } & \multicolumn{2}{c}{ Número de citações } & \multirow{2}{*}{$\boldsymbol{p}^{*}$} \\
\cline { 2 - 3 } & $\mathbf{1 0}$ & $<\mathbf{1 0}$ & \\
\hline Estados Unidos & $78(47 \%)$ & $39(39 \%)$ & 0,6604 \\
Japão & $15(9 \%)$ & $11(11 \%)$ & \\
Europa & $55(33 \%)$ & $38(38 \%)$ & \\
Outros & $19(11 \%)$ & $12(12 \%)$ & \\
\hline${ }^{*}$ Teste G & & &
\end{tabular}

Em relação ao idioma utilizado na redação dos artigos científicos observou-se que o inglês predominou com 276 artigos publicados, perfazendo $93 \%$ de todas as publicações (Figura 8). Inicialmente, os principais idiomas da ciência eram o latim e o italiano, mas aos poucos foram cedendo lugar para outras línguas até a consolidação do inglês como a língua franca da ciência (MEADOWS 1974). Esse fato tem suas origens no papel de dominador que o império britânico exerceu nos últimos séculos assim como no papel de grande potência econômica. É, portanto, 
inquestionável a presença forte da língua inglesa como componente fundamental na ciência global.

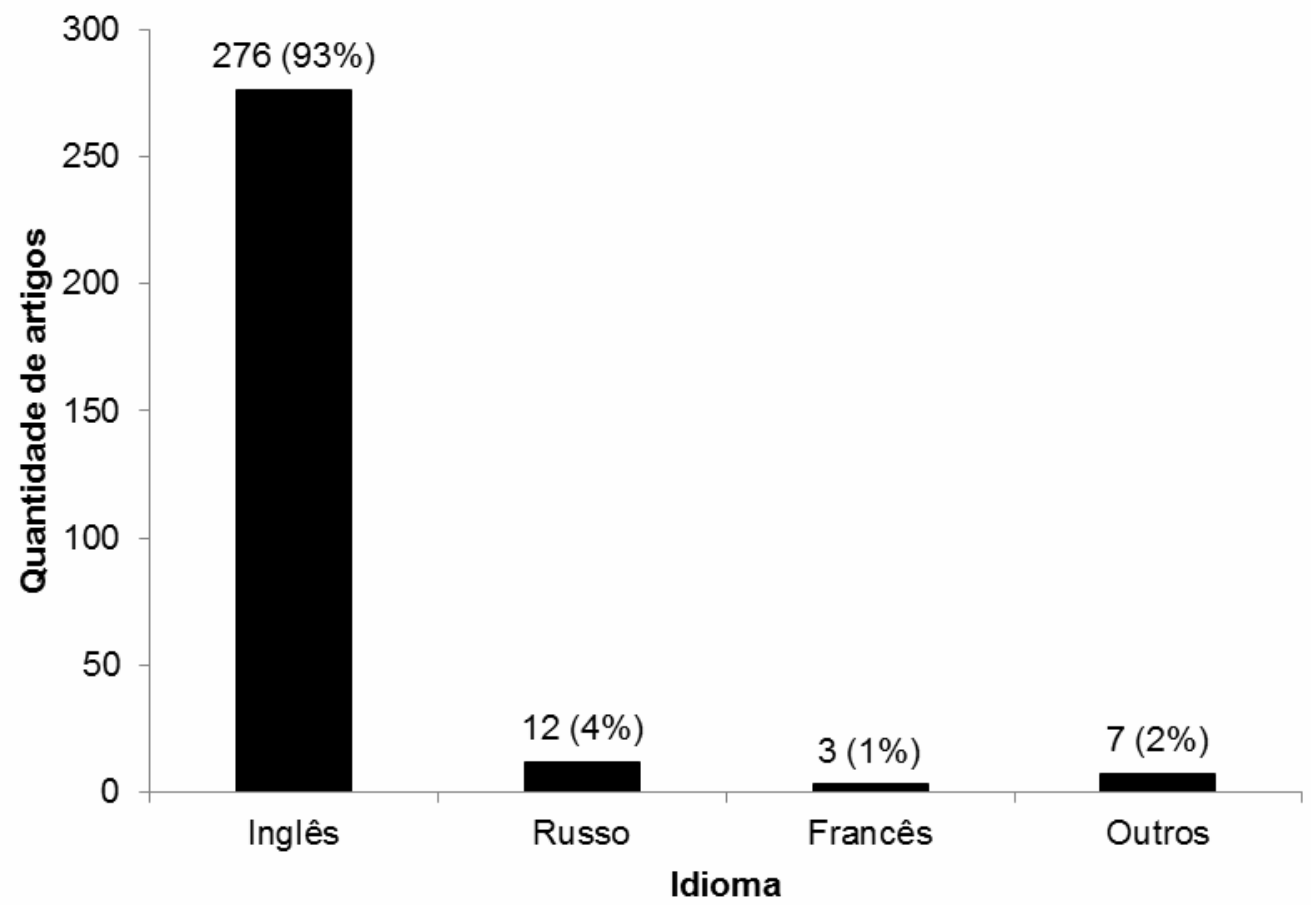

FIGURA 8. Idiomas mais utilizados nas publicações sobre radiação ionizante e danos no DNA no campo da genética.

Dos 298 artigos analisados, 198 enfatizaram a correlação entre patologias e os danos no DNA. Destas patologias a que mais se destacou foi o câncer SOE (sem outra especificação), com um total de 81 artigos (41\%). A segunda patologia mais expressiva, com 36 artigos (18\%), relacionou-se com as doenças do reparo, destacando a Ataxia-telangiectasia (Tabela 3).

A Radiação lonizante (RI) é um conhecido agente carcinogênico. O potencial da RI para causar tumores foi reconhecido logo após sua descoberta, quando o primeiro tumor radioinduzido foi descrito em 1902. Desde então, muitos estudos para a compreensão dos mecanismos celulares e moleculares da carcinogênese radioinduzida foram desenvolvidos (MORGAN, 2003).

NAGAR et al. (2003) afirmam que a interação da RI com células humanas pode afetar uma série de processos nestas, e se o mecanismo de reparo dessas células não for eficiente, poderá ocorrer efeitos biológicos nocivos ao organismo humano. O efeito cumulativo no organismo, causado pela radiação ionizante em baixas doses, em populações expostas, pode gerar transformações celulares com potencial de genotoxicidade. Atualmente existe um grande número de publicações que relacionam agravos, em particular o câncer, a exposição crônica a baixas doses de radiação ionizante. Estes estudos evidenciam que a célula reage a baixos níveis deste tipo de radiação, acionando mecanismos com potencial efeito carcinogênico (AYRES et al., 2007). 
TABELA 3. Principais doenças referidas nos 298 artigos selecionados.

\begin{tabular}{lcc}
\hline Doenças Relacionadas & $\mathbf{n}$ & \% \\
\hline Câncer SOE & 81 & 41 \\
Doenças de Reparo & 36 & 18 \\
Infertilidade & 14 & 7 \\
Leucemias/ Linfomas & 11 & 6 \\
Microcefalia & 6 & 3 \\
Outros & 50 & 25 \\
\hline Total & $\mathbf{1 9 8}$ & $\mathbf{1 0 0}$ \\
\hline
\end{tabular}

MOREIRA (2004) afirma que o avanço das pesquisas se dá à medida que cresce o número de objetos da informação. Logo, os dados deste estudo também corroboram esse fato, uma vez que os Cânceres da mama, de pulmão e do colorretal, apresentam grande incidência na população e foram também os tipos de neoplasias mais estudados.

\section{CONCLUSÕES}

Observou-se que houve a tendência de aumento no número de publicações ao longo dos anos, com um pico de publicações no ano de 2013 sendo que os trabalhos foram, na maioria, artigos originais.

Verificou-se que os periódicos e as instituições que mais publicaram são de países desenvolvidos. A maior parte dos estudos envolve patologias, e entre as doenças investigadas, o câncer obteve maior número de trabalhos publicados.

Portanto, conclui-se que há interesse em relação ao estudo de danos no DNA causados por radiação ionizante, uma vez que estes danos podem ser responsáveis por inúmeros efeitos biológicos desfavoráveis à saúde humana.

\section{REFERÊNCIAS}

ARDENGHI, T. M.; BAYARDO, R. B.; OLIVEIRA, J. X. Estimativa de Risco Biológico das Radiações lonizantes na Medula Óssea, Glândula Tireóide e Glândulas Salivares: Considerações sobre Pacientes Infantis. Jornal Brasileiro de Odontopediatria e Odontologia do Bebê, v. 6, n. 32, p. 339-43, 2003.

AYRES, M.; AYRES JÚNIOR, M.; AYRES, D. L.; SANTOS, A. A. S. BioEstat: Aplicações estatísticas na área de ciências bio-médicas. 4. ed. Belém:editora, 2007.

CARNEIRO, F. M.; NABOUT, J.C.; BINI, L.M. Trends in the scientific literature on phytoplankton. Limnology, v. 9, pp. 153-158. 2008.

CURRÁS, E.; BARREIRO, E. W. Integration in Europe of human genetics results obtained by Spaniards in the USA: A historical perspective. Scientometrics, v. 75, p. 473-493, 2008. 
FLÔR, R. C.; KIRCHHOF, A. L. C. Uma prática educativa de sensibilização quanto à exposição à radiação ionizante com profissionais de saúde. Revista Brasileira de Enfermagem, v. 59, n. 3 p. 274-278, 2006.

HEY T.; TANSLEY S.; TOLLE K. (2009). The fourth paradigm: Data intensive scientific discovery. Redmond, WA. http://research.microsoft.com/enus/collaboration/fourthparadigm. Acesso em: 9 jun 2016.

MACIAS-CHAPULA, C. A. O papel da informetria e da cienciometria e sua perspectiva nacional e internacional. Ciência da informação, Brasília, v. 27, n. 2, p.134-140, 1998.

MEADOWS, D.L.; The dynamics of growth in a finite world, Wright-Allen Press, Cambridge, Mass. 1974.

MORGAN, W. F. Is there a common mechanism underlying genomic instability, bystander effects and other nontargeted effects of exposure to ionizing radiation? Oncogene, v. 22, n. 45, p. 7094-9, Oct 13. 2003.

NAGAR, S.; SMITH, L. E.; MORGAN, W. F. Characterization of a novel epigenetic effect of ionizing radiation: the death-inducing effect. Cancer Research, v. 63, n. 2, p. 324-8, Jan 152003.

NONATO, R. M. S. Produção científica: por que medir? O que medir? Revista digital de Biblioteconomia e Ciência da informação, v.1, n.1, p. 22-38, 2003.

QUIXABEIRA, V. B.; NABOUT, J.C.; RODRIGUES, F. M. Trends in genetic literature with the use of flow cytometry. Cytometry Part A, v. 77A, pp. 207-210, 2010.

THOMAZ, P.G.; ASSAD, R.S.; MOREIRA, L.P.P. Uso do Fator de Impacto e do Índice $\mathbf{H}$ para Avaliar Pesquisadores e Publicações. Instituto do Coração HCFMUSP - São Paulo; 2011.

VELUDO, P. C. Efeitos da radiação $X$ e níveis de exposição em exames imagiológicos: inquéritos a clínicos gerais. 2011. 65 f. Dissertação (Mestrado em Saúde Pública) - Curso de Faculdade de Medicina da Universidade de Coimbra, Universidade de Coimbra, Coimbra, 2011.

VERBEEK, A.; DEBACKERE, K.; LUWEL, M.; ZIMMERMANN, E. Measuring progress and evolution in science and technology - I: The multiple uses of bibliometric indicators. International Journal of Management Review., Oxford, v. 4, 2002.

WUEHRMANN, A. H.; MANSON-HIG L. R. Perigos e proteção. In: Radiologia dentária. 5aㅡ ed. Rio de Janeiro: Guanabara Koogan; 1985. 